\title{
Crescimento vascular em membrana do saco vitelínico e desenvolvimento embrionário de codornas japonesas (Coturnix japonica) expostas a campo magnético de baixa frequência
}

\author{
[Vascular growth in yolk sac membrane and embryonic development of Japanese quail
}

(Coturnix japonica) exposed to low frequency magnetic field]

\author{
M.M.S. Silva, T.H.S. Almeida, E.V.L. Costa, J.E.S. Silva, R.A. Nogueira* \\ Universidade Federal Rural de Pernambuco - Dois Irmãos - Recife, PE
}

\section{RESUMO}

O objetivo deste trabalho foi observar a influência do campo magnético $(\mathrm{CM})$ de baixa frequência na membrana do saco vitelínico (MSV) e no desenvolvimento do embrião de codornas japonesas (Coturnix japonica) em 72 horas de incubação. Ovos fertilizados foram expostos a nove horas consecutivas de CM, sendo um grupo a partir das 48 horas e o outro a partir das 63 horas de incubação. A quantificação da vascularização da MSV foi determinada pela obtenção da dimensão fractal por meio dos métodos de boxcounting e de dimensão de informação, enquanto o peso corporal e o percentual de comprimento cefálico dos embriões foram utilizados como parâmetros de desenvolvimento embrionário. O CM não causou diferenças significativas na densidade vascular da MSV nem no desenvolvimento embrionário, quando comparados ao grupo controle.

Palavras-chave: campo magnético, dimensão fractal, embriões de codorna, membrana do saco vitelínico, vascularização

\begin{abstract}
The aim of this study was to observe the influence of the low frequency magnetic field (MF) on the yolk sac membrane (YSM) and embryonic development of Japanese quail (Coturnix japonica) in 72 hours of incubation. Fertilized eggs were exposed to 9 consecutive hours of MF, with a group from 48 hours and the second group from 63 hours of incubation. The evaluation of YSM vascularization was determined by the fractal dimensions obtained through box-counting method and information dimension, while body weight of the embryo and percentage of cephalic length were used as parameters for embryo development. The MF caused no significant differences in vessel density in the YSM, nor in the embryonic development considering the body weight and percentage cephalic length, when were compared to the control group.
\end{abstract}

Keywords: magnetic field, fractal dimension, quail embryos, yolk sac membrane, vascularization

\section{INTRODUÇÃO}

A avaliação do processo de crescimento vascular tem utilizado alguns modelos in vivo, entre eles a membrana do saco vitelínico (MSV) e a membrana corioalantóide (MCA) de embriões de aves, devido a sua acessibilidade à observação e experimentação. A MSV é constituída das três camadas germinativas nos estágios iniciais, contendo células mesodérmicas e endodérmicas após a expansão do celoma extraembrionário
(Sheng, 2010; Bauer et al., 2013). A MSV é dividida em área vitelínica (região da membrana que ainda não contém células do mesoderma) e área vasculosa (local onde ocorre a hematopoese e vasculogênese no saco vitelino - SV). Com o desenvolvimento embrionário, a MCA ou alantocórion se forma da fusão do córion com o alantoide (Sheng, 2010).

Nas primeiras 72 horas do desenvolvimento embrionário de aves, uma rede vascular

Recebido em 31 de agosto de 2012

Aceito em 12 de dezembro de 2013

*Autor para correspondência (corresponding author)

E-mail: ran.pe@terra.com.br 
extraembrionária se forma no $\mathrm{SV}$ a partir da diferenciação dos hemangioblastos, que resultam na formação de um plexo capilar primitivo, um processo denominado de vasculogênese. Posteriormente, ocorrerá a angiogênese, que é a formação de novos vasos a partir dos vasos preexistentes do plexo capilar (Dias et al., 2002; Senegaglia et al., 2009).

A MSV e a MCA de aves têm sido propostas como modelo para avaliação de efeitos de agentes físicos e químicos sobre o crescimento vascular. Nestes modelos, tem sido investigada a ação de campos magnéticos (CM) de diferentes intensidades e frequências, inclusive de CM de baixa frequência (3 a $3.000 \mathrm{~Hz}$ ). Ruggiero et al. (2004) detectaram a inibição da angiogênese da rede vascular da MCA de embriões de galinha expostos a um CM estático de intensidade 0,2 $\mathrm{T}$. Wang et al. (2009) observaram um efeito inibitório sobre a vascularização em MCA de embriões de galinha expostos a um CM estático e de intensidade entre 0,2 e 0,4 T. Balanezhad et al. (2010) mostraram que um CM de $40 \mathrm{mT}$ e 50 $\mathrm{Hz}$ pode inibir a angiogênese em MCA de embrião de galinha. Costa et al. (2013) observaram a inibição da formação da rede vascular em MSV de embriões de codorna, quando submetidos, durante seis e nove horas por dia (duas e três horas por sessão, a cada oito horas), a um CM de $60 \mathrm{~Hz}$ e $1 \mathrm{mT}$.

Os efeitos da exposição de embriões de aves a CM também são variáveis. CM com frequência de $50 \mathrm{~Hz}$ e diferentes intensidades $(1,33$ a 7,32 $\mathrm{mT}$ ) promoveram alterações morfológicas, de comprimento craniocaudal e peso de embriões de galinha expostos durante 24 horas antes do início da incubação (Lahijani e Sajadi, 2004). RodaMurillo et al. (2005) observaram que a exposição de ovos fertilizados ao $\mathrm{CM}$ de $50 \mathrm{~Hz}$ e intensidade de $1 \mu \mathrm{T}, 0,5 \mathrm{mT}$ ou $1 \mathrm{mT}$ também resultou em alterações morfológicas dos embriões no estágio $41 \mathrm{H}-\mathrm{H}$ (estágio 41 de Hamburger-Hamilton), enquanto no estágio 46 $\mathrm{H}-\mathrm{H}$, tanto o peso corporal quanto os diâmetros craniais dos embriões sofreram redução diretamente proporcional à intensidade do CM. $\mathrm{O}$ objetivo deste trabalho foi investigar a influência de campo magnético de frequência extremamente baixa $(60 \mathrm{~Hz})$ sobre a vasculogênese e angiogênese extraembrionária e sobre o desenvolvimento do embrião de codornas japonesas (Coturnix japonica) durante as primeiras 72 horas de incubação.

\section{MATERIAL E MÉTODOS}

Sessenta ovos fertilizados de codornas japonesas (Coturnix japonica) com 20 semanas de idade foram obtidos de criadouro local e selecionados considerando-se aqueles que apresentavam formato regular e casca íntegra. Os ovos foram desinfectados com solução de peróxido de hidrogênio $3 \%$ e distribuídos em três incubadoras (Chocmaster - CHP54) com temperatura mantida a $37,5^{\circ} \mathrm{C}$ e umidade relativa em torno de $60 \%$ (Pedroso et al., 2006). Os ovos foram mantidos na posição horizontal e virados automaticamente a cada duas horas, entre a $24^{\mathrm{a}} \mathrm{e}$ $48^{\mathrm{a}}$ horas de incubação.

Após 48 horas do início da incubação, foi efetuada a abertura da casca (janela) dos ovos (aproximadamente $3 \mathrm{~cm}^{2}$ ), e, com auxílio de seringa estéril, removeram-se $2,5 \mathrm{~mL}$ de albúmen para facilitar a visualização do embrião e da vascularização extraembrionária. Após a retirada do albúmen, a janela foi selada com parafilme para evitar desidratação do embrião e os ovos foram reintroduzidos na incubadora, para prosseguir o processo de desenvolvimento embrionário. A partir desse momento, o sistema de viragem da incubadora foi desativado, para evitar extravasamento do conteúdo do ovo em consequência de remoção de parte de sua casca.

Para o experimento, foram constituídos três tratamentos ( $\mathrm{n}=20$ ovos/tratamento), sendo dois grupos expostos durante nove horas consecutivas a um CM de intensidade de $1 \mathrm{mT}$ e frequência de $60 \mathrm{~Hz}$, gerado por uma bobina de Helmholtz (Phywe, Alemanha), e um grupo controle shamexposto. A exposição ao campo foi realizada colocando-se a incubadora entre duas bobinas circulares planas (Fig. 1). Um grupo foi exposto a partir da $48^{\mathrm{a}}$ hora de incubação, e o outro a partir de $63^{\mathrm{a}}$ hora de incubação. Para o grupo controle sham-exposto, a bobina foi mantida desligada. As análises foram realizadas ao final de 72 horas de incubação. 


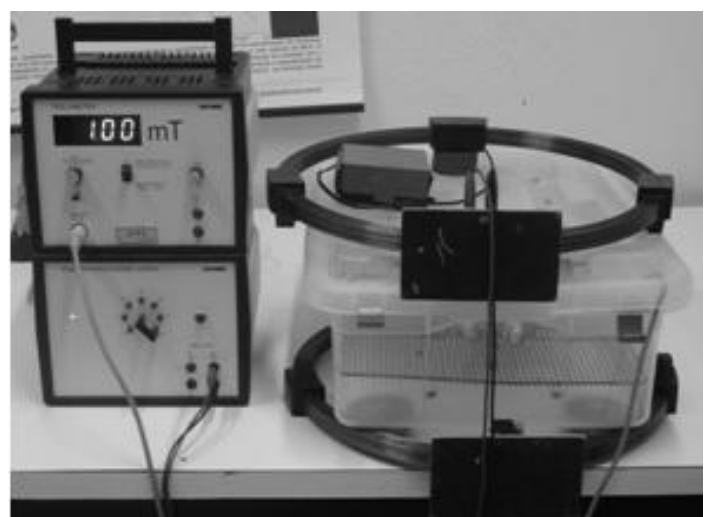

Figura 1. Ovos de codorna japonesa incubados a $37,5^{\circ} \mathrm{C}$ e expostos a $\mathrm{CM}$ de $1 \mathrm{mT}$ e $60 \mathrm{~Hz}$.

Para análise da rede vascular da MSV dos embriões, foi realizada a captura das imagens com câmera digital (1920 x 1080 pixels). As imagens da vascularização foram submetidas aos processos de segmentação manual e automática, método que tem por finalidade separar os vasos sanguíneos do restante da imagem. A segmentação manual foi feita por meio do programa Microsoft $^{\circledR}$ Paint, utilizando-se a largura de 1 pixel para cobertura dos vasos, independentemente de seus calibres, processo denominado esqueletização. Em seguida, as imagens foram binarizadas, tornando o fundo de imagem em preto e vasos em branco. Para a segmentação automática, foi utilizado um algoritmo disponível no programa Matlab, versão 7.8 (Mathwork, Estados Unidos). Após o tratamento das imagens, as dimensões fractais da vascularização da MSV foram calculadas por meio do software Benoit ${ }^{\mathrm{TM}} 1.3$ Fractal Analysis System (TruSoft International, Estados Unidos), utilizando-se os métodos de dimensão de box- counting $\left(D_{b c}\right)$ e de dimensão de informação $\left(\mathrm{D}_{\text {inf }}\right)$, como descrito em Kunicki et al. (2009).

Após a captura das imagens da MSV, realizou-se a dissecação dos embriões, com posterior pesagem em balança analítica e registro fotográfico deles para cálculo do percentual de comprimento cefálico (PCC) ao final de 72 horas de incubação (Fig. 2). O percentual de comprimento cefálico (PCC), usado como parâmetro de crescimento embrionário, é calculado de acordo com a seguinte expressão: [comprimento do eixo da cabeça à flexura cervical $\div$ (comprimento do eixo da cabeça à flexura cervical + comprimento do eixo da flexura cervical à flexura caudal)] x 100, como descrito na literatura (Dias et al., 2008). Observar que esta é uma medida relativa do comprimento cefálico em relação ao corpo de embrião.

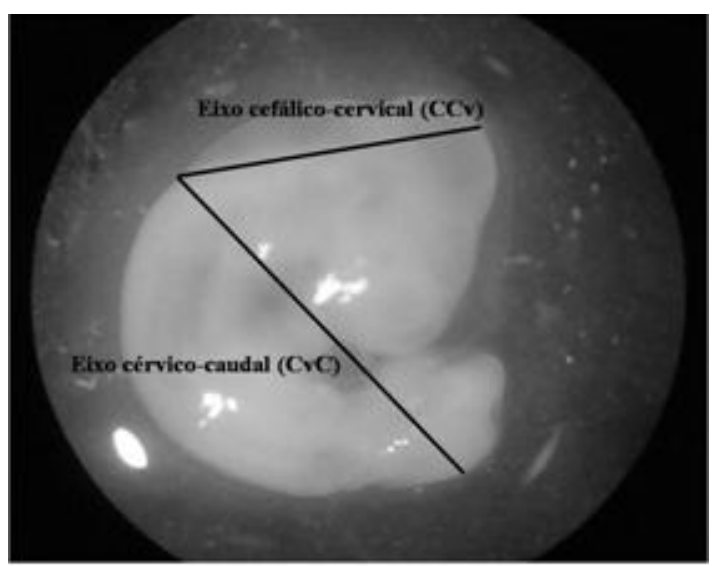

Figura 2. Medição do eixo cefálico-cervical $(\mathrm{CCv})$ e do eixo cérvico-caudal $(\mathrm{CvC})$ para cálculo do percentual de comprimento cefálico do embrião. 
Os resultados foram analisados utilizando-se o teste de Kruskal-Wallis com o teste pos-hoc de Dunn, admitindo-se $\mathrm{p}<0,05$.

\section{RESULTADOS E DISCUSSÃO}

A vascularização apresenta padrão de ramificações complexo em sua arquitetura, com características de autossimilaridade, portanto o sistema vascular sanguíneo pode ser considerado uma estrutura fractal. Por essa razão, possíveis variações apresentadas na vasculatura, decorrentes de moléculas bioativas ou fatores físicos, podem ser detectadas por meio da determinação de suas dimensões fractais (Masters, 2004; Silva et al., 2012).

No presente trabalho, a exposição de embriões de codorna japonesa (Coturnix japonica) a CM extremamente baixo $(60 \mathrm{~Hz}$ e $1 \mathrm{mT})$ durante nove horas não promoveu alteração na vascularização da MSV avaliada em 72 horas de incubação (estágio $18 \mathrm{H}-\mathrm{H}$ ), independentemente da aplicação do CM ter ocorrido a partir da $48^{\mathrm{a}}$ ou da $63^{\mathrm{a}}$ hora de incubação, quando estes embriões foram comparados ao grupo controle, quantificada por meio da dimensão fractal (Fig. 3).

A quantificação do processo vascular, por meio das dimensões fractais, pode ser observada na Tab. 1. Nesta tabela, são mostrados os valores medianos das dimensões fractais obtidos pela aplicação dos métodos de box-counting e de dimensão de informação, usados para quantificar a dinâmica do crescimento vascular na MSV quando submetida ao CM de $60 \mathrm{~Hz}$. Observa-se que não houve diferenças significativas entre os grupos expostos e controle.

Ruggiero et al. (2004), ao utilizarem a técnica de contagem de vasos, verificaram que a exposição de embriões de galinhas submetidos a um CM de $0,2 \mathrm{mT}$, durante três horas, no $10^{\circ}$ dia de incubação inibiu a angiogênese sem alterar a vasculogênese. Wang et al. (2009) observaram um efeito inibitório sobre a angiogênese caracterizado por uma redução tanto do número quanto das bifurcações de vasos na MCA de embriões de galinha expostos ao CM de 0,2 a 0,4 T, no segundo, sétimo e nono dias de incubação. Balanezhad et al. (2010) verificaram que houve redução significativa da vascularização desta membrana, tanto no número quanto no comprimento dos vasos, quando exposta ao $\mathrm{CM}$ de $0,04 \mathrm{~T}$ durante quatro horas no $10^{\circ}$ dia de incubação. Estes resultados poderiam ser decorrentes do fato de que nesta membrana ocorre intensa neovascularização entre o quarto e o oitavo dia do desenvolvimento embrionário.

Costa et al. (2013), ao utilizarem a dimensão fractal para parametrizar o processo vascular, observaram inibição do processo de vascularização da MSV de embriões de codorna expostos três vezes ao dia a um CM de $1 \mathrm{mT}$ e $60 \mathrm{~Hz}$, com duração de duas e três horas, aplicado entre 48 e 72 horas de incubação. Entretanto, a exposição dos embriões durante 1, 4 e 24 horas não promoveu alteração na rede vascular da MSV, corroborando os resultados obtidos no presente trabalho, e sugere a existência de um "efeito janela" em relação ao tempo de exposição. Esse efeito pode estar relacionado à interação do $\mathrm{CM}$ com fatores de crescimento (Ruggiero et al., 2004) e outros mecanismos relacionados ao processo de vascularização (Costa et al., 2013), ou com a cinética dos canais de cálcio, envolvidos na regulação dos processos de vascularização (Morabito et al., 2010).

Além de ser nicho e fonte primordial de células para a eritropoiese primitiva, o SV contém a substância utilizada pelo embrião durante todo o período de incubação, a qual constitui fonte de vitaminas lipossolúveis, ácidos graxos e energia, conhecida como vitelo (Tesar et al., 2008), e é fundamental para o desenvolvimento embrionário.

Na MSV, após a diferenciação das ilhotas sanguíneas em linhagens hematopoiéticas e endoteliais, ocorre uma agregação dessas ilhotas, dando origem a um plexo capilar primitivo (Hendrix et al., 2003), e antes que a circulação comece (estágio $10 \mathrm{H}-\mathrm{H}$ ), uma rede vascular bem organizada pode ser observada na área vasculosa da MSV. Sheng (2010), ao utilizar marcadores moleculares, observou que a eritropoiese no SV ocorre avidamente pelo menos até o estágio 10 $\mathrm{H}-\mathrm{H}$ e se reduz de forma significativa até o estágio $15 \mathrm{H}-\mathrm{H}$, o que sugere que, entre os estágios 12 e $15 \mathrm{H}-\mathrm{H}$, a medula óssea assume a função de principal órgão eritropoiético, embora o SV continue a contribuir para este processo até a eclosão. 


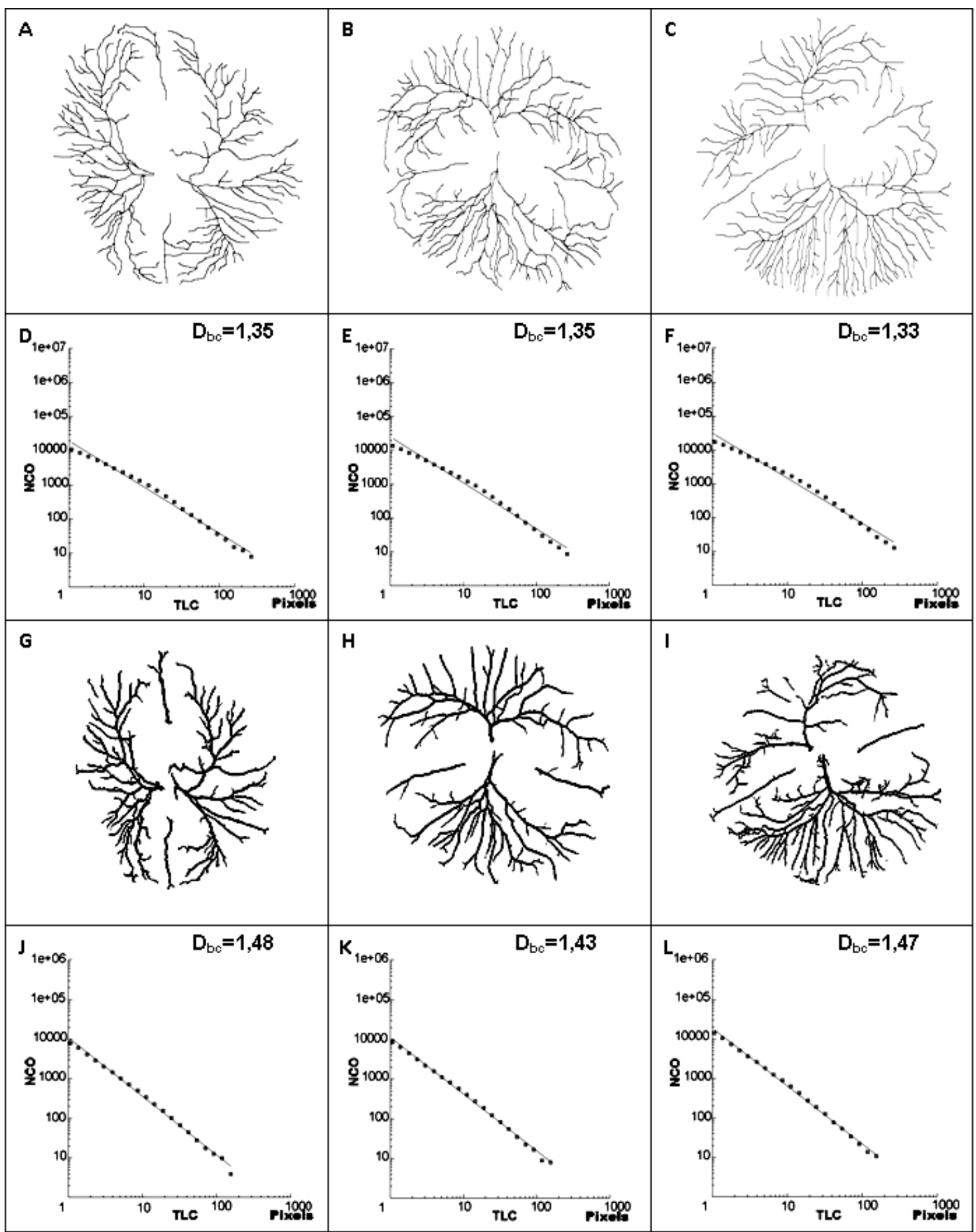

Figura 3. Imagens esqueletizadas (A, B e C) e segmentadas (G, H e I) da vascularização da membrana do saco vitelínico dos embriões de codorna dos grupos expostos a campo magnético de $1 \mathrm{mT}$ e $60 \mathrm{~Hz}$ em 48 horas de incubação (A e G), 63 horas de incubação (B e H) e do controle (C e I) com os gráficos da dimensão fractal obtida pelo método de box-counting (D e J, E e K, F e L, respectivamente). NCO (número de caixas ocupadas pela rede vascular). TLC (tamanho dos lados das caixas). 
Tabela 1. Valores das dimensões fractais (mediana \pm desvio interquartílico) obtidos pelos métodos de Boxcounting $\left(\mathrm{D}_{\mathrm{bc}}\right)$ e de dimensão de informação $\left(\mathrm{D}_{\text {inf }}\right)$

\begin{tabular}{|c|c|c|c|c|c|}
\hline Exposição & & $48^{\mathrm{a}} \mathrm{h}$ & $63^{a} h$ & Controle & \\
\hline & $\mathrm{N}$ & \multicolumn{2}{|c|}{ Esqueletização } & & $\mathrm{P}$ \\
\hline $\mathrm{D}_{\mathrm{bc}}$ & 11 & $1,36 \pm 0,09$ & $1,37 \pm 0,06$ & $1,33 \pm 0,09$ & 0,74 \\
\hline$D_{\text {inf }}$ & 11 & $1,38 \pm 0,07$ & $1,38 \pm 0,07$ & $1,36 \pm 0,07$ & 0,49 \\
\hline \multicolumn{6}{|c|}{ Segmentação } \\
\hline $\mathrm{D}_{\mathrm{bc}}$ & 11 & $1,48 \pm 0,11$ & $1,43 \pm 0,14$ & $1,47 \pm 0,14$ & 0,37 \\
\hline$D_{\text {inf }}$ & 11 & $1,51 \pm 0,09$ & $1,49 \pm 0,16$ & $1,52 \pm 0,11$ & 0,60 \\
\hline
\end{tabular}

Diferença estatisticamente significativa para $\mathrm{p}<0,05$.

No presente trabalho, possíveis efeitos de CM de $1 \mathrm{mT}$ sobre o desenvolvimento embrionário foram avaliados pelos parâmetros de peso corporal e percentual de comprimento cefálico dos embriões de codorna japonesa. Diferenças significativas não foram observadas entre o peso corporal do grupo controle e dos grupos expostos ao $\mathrm{CM}$ com intensidade de $1 \mathrm{mT}$ e $60 \mathrm{~Hz}$, durante nove horas consecutivas, a partir da $48^{\mathrm{a}}$ hora (estágio $13 \mathrm{H}-\mathrm{H})$ e da $63^{\mathrm{a}}$ hora (estágio 17 H-H) de incubação, avaliados em 72 horas de incubação (estágio 18 H-H). Também não se verificou alteração significativa no percentual de comprimento cefálico dos embriões dos referidos grupos experimentais (Tab. 2).

Tabela 2. Valores obtidos para peso corporal (PC) e percentual de comprimento cefálico (PCC) dos embriões (mediana \pm desvio interquartílico) expostos a campo magnético de $1 \mathrm{mT}$ e $60 \mathrm{~Hz}$ e no controle.

\begin{tabular}{|c|c|c|c|c|c|c|c|}
\hline \multirow[t]{2}{*}{ Parâmetros } & \multicolumn{6}{|c|}{ Exposição } & \multirow[b]{2}{*}{$\mathrm{p}$} \\
\hline & $\mathrm{N}$ & $48 \mathrm{~h}$ & $\mathrm{~N}$ & $63 \mathrm{~h}$ & $\mathrm{~N}$ & Controle & \\
\hline $\mathrm{PC}(\mathrm{g})$ & 16 & $19,25 \pm 6,76$ & 14 & $16,15 \pm 7,26$ & 12 & $20,67 \pm 5,98$ & 0,10 \\
\hline $\mathrm{PCC}(\mathrm{mm})$ & 16 & $41,34 \pm 3,60$ & 14 & $42,71 \pm 1,60$ & 12 & $42,33 \pm 2,84$ & 0,41 \\
\hline
\end{tabular}

Diferença estatisticamente significativa para $\mathrm{p}<0,05$.

Em embriões de galinhas (Gallus domesticus), o CM extremamente baixo exerce diversos efeitos. Lahijani e Sajadi (2004) verificaram os efeitos decorrentes da exposição de embriões de galinha a campos magnéticos de $50 \mathrm{~Hz}$ com diferentes intensidades (1,33 a 7,32 mT), expostos durante 24 horas antes do início da incubação. Os resultados mostraram que, no nono dia de incubação (estágio $35 \mathrm{H}-\mathrm{H}$ ), apenas os grupos expostos a CM de 4,19 a 6,65 mT apresentaram taxa de anormalidade significativa, como malformação de vértebras, costelas e bico. Além disso, foi observada redução significativa no comprimento craniocaudal e no peso dos embriões expostos a CM com intensidade de 4,39 e 5,52mT, em comparação com os grupos controle e sham-expostos. De acordo com estes autores, os resultados obtidos revelaram que campos eletromagnéticos de $50 \mathrm{~Hz}$ podem induzir alterações no desenvolvimento dos embriões de galinha, dependendo da intensidade do campo magnético de baixa frequência.

Roda-Murillo et al. (2005) observaram que a exposição de ovos fertilizados ao CM de $50 \mathrm{~Hz}$ e intensidade de $1 \mu \mathrm{T}, 0,5 \mathrm{mT}$ ou $1 \mathrm{mT}$ resultou em alterações morfológicas dos embriões. Em 15 dias de incubação (estágio $41 \mathrm{H}-\mathrm{H}$ ), houve redução do peso corporal dos embriões dos grupos tratados em relação ao controle, enquanto nesse mesmo período o aumento do diâmetro vertical cranial e a diminuição do diâmetro transverso cranial foram observados no grupo exposto ao CM de $1 \mathrm{mT}$. Por outro lado, em 21 dias de incubação (estágio $46 \mathrm{H}-\mathrm{H}$ ), tanto o peso corporal quanto os diâmetros craniais dos embriões sofreram redução diretamente proporcional à intensidade do CM.

Além de temperatura e umidade (Dias et al., 1998; Pedroso, 2006), os campos magnéticos extremamente baixos são fatores físicos que podem conduzir a alterações do crescimento e desenvolvimento embrionário de aves. Entretanto, esses efeitos são diretamente relacionados ao período de desenvolvimento do embrião, bem como à intensidade do campo magnético, além do tempo de exposição. 


\section{Crescimento vascular...}

\section{CONCLUSÃO}

A exposição de embriões de codornas japonesas a um campo magnético de $60 \mathrm{~Hz}$ e $1 \mathrm{mT}$, por um período de 9 horas, não foi capaz de alterar o padrão vascular na membrana do saco vitelínico. O desenvolvimento dos embriões dos grupos expostos ao campo magnético também não sofreu alteração quando comparados ao grupo controle avaliados em 72 horas de incubação.

\section{REFERÊNCIAS}

BALANEZHAD, S.Z.; PARIVAR, K.; BAHARARA J. et al. The effect of extremely low frequency electromagnetic field on angiogenesis. Res. J. Envir. Sci., v.4, p.300-304, 2010.

BAUER, R.; PLIESCHNIG, J.A.; FINKES, T.; RIEGLER, B.; HERMANN, M.; SHNEIDER, W.J. The developing chicken yolk sac acquires nutrient transport competence by an orchestrated differentiation process of its endodermal epithelial cells. JBC. v.288, p.1088-1098, 2013.

COSTA, E.V.L.; JIMENEZ, G.C.; BARBOSA, C.T.F. et al. Fractal analysis of extra-embryonic vascularization in japanese quail embryos exposed to extremely low frequency magnetic fields. Bioelectromagnetics, v.34, p.114-121, 2013.

DIAS, P.F; SANTA, U.F.D. Características do desenvolvimento embrionário de Gallus gallus domesticus, em temperaturas e períodos diferentes de incubação. Braz. J. Vet. Res. Anim. Sci., v.35, p.233235, 1998.

DIAS, P.F.; RIBEIRO-DO-VALLE, R.M.; MARASCHIM, R.P. et al. Novos moduladores da formação de vasos sanguíneos. Biotecnologia Cienc. Desenvolv., v.25, p. 28-34, 2002.

DIAS, P.F.; SIQUEIRA JR., J.M; MARASCHIN, M. et al. A polysaccharide isolated from the brown seaweed Sargassum stenophyllum exerts antivasculogenic effects evidenced by modified morphogenesis. Microvasc. Res., v.75, p.34-44, 2008.

HENDRIX, M.J.C.; SEFTOR, E.A.; HESS, A.R. et al. Vasculogenic mimicry and tumour-cell plasticity: lessons from melanoma. Nat. Rev. Cancer, v.3, p.411442, 2003.

KUNICKI, A.C.B.; OLIVEIRA, A.J.; MENDONÇA, M.B.M. et al. Can the fractal dimension be applied for the early diagnosis of non-proliferative diabetic retinopathy? Braz. J. Med. Biol. Res., v.42, p.930-934, 2009.
LAHIJANI, M.S.; SAJADI, K. Development of preincubated chicken eggs following exposure to 50 $\mathrm{Hz}$ electromagnetic fields with $1.33-7.32 \mathrm{mT}$ flux densities. Ind. J. Exp. Boil., v.42, p.858-865, 2004

MASTERS, B.R. Fractal analysis of the vascular tree in the human retina. Annu. Rev. Biomed. Eng., v.6, p. 427-52, 2004

MORABITO, C.; ROVETTA, F.; BIZZARRI, M. et al. Modulation of redox status and calcium handling by extremely low frequency electromagnetic fields in C2C12 muscle cells: A real-time, single-cell approach. Free Radic. Biol. Med. v.48, p.579-589, 2010.

PEDROSO, A.A.; CAFÉ, M.C.; LEANDRO, N.S.M. et al. Desenvolvimento embrionário e eclodibilidade de ovos de codornas armazenados por diferentes períodos e incubados em umidades e temperaturas distintas. Rev. Bras. Zootec., v.35, p.2344-2349, 2006.

RODA-MURILLO, O.; RODA-MORENO, J.A.; PASCUAL-MORENILLA, M.T. Effects of lowfrequency magnetic fields on different parameters of embryo of Gallus Domesticus. Electromagnetic Biol. Med., v.24, p.55-62, 2005.

RUGGIERO, M.; BOTTARO, D.P.; LIGURI, G. et al. 0.2T Magnetic field inhibits angiogenesis in chick embryo chorioallantoic membrane. Bioelectromagnetics. v.25, p.390-396, 2004.

SENEGAGLIA, A.C.; REBELATTO, K.L.C.; SUSS, P.H. et al. Expansão de células-tronco da medula óssea e do sangue de cordão umbilical humano. Rev. Bras. Hematol. Hemoter., v.31, p.9-14, 2009.

SHENG, G. Primitive and definitive erythropoiesis in the yolk sac: a bird's eye view. Int. J. Dev. Biol., v.54, p.1033-1043, 2010 .

SILVA, J.E.S; MOURA, A.M.A.; NOGUEIRA, R.A. Efeito dos ácidos graxos essenciais sobre lipidemia e vascularização da membrana vitelina de codornas japonesas Arq. Bras. Med. Vet. Zootec., v.64, p.1603612,2012

TESAR, D.B.; CHEUNG, E.J.; BJORKMAN, P.J. The chicken yolk sac IgY receptor, a mammalian mannose receptor family member, transcytoses $\operatorname{IgY}$ across polarized epithelial cells. Mol. Biol Cell., v.19, p.1587-1593, 2008

WANG, Z.; YANG, P.; XU, H. et al. Inhibitory effects of a gradient static magnetic field on normal angiogenesis. Bioelectromagnetics, v.30, p.446-453. 2009. 